\title{
Reactant gas transport and cell performance of proton exchange membrane fuel cells with tapered flow field design
}

\author{
H.C. Liu ${ }^{\text {a }}$, W.M. Yan ${ }^{\mathrm{a}, *}$, C.Y. Soong ${ }^{\mathrm{b}}$, Falin Chen ${ }^{\mathrm{c}}$, H.S. Chu ${ }^{\mathrm{d}}$ \\ ${ }^{a}$ Department of Mechatronic Engineering, Huafan University, Shih-Ting, Taipei 223, Taiwan, ROC \\ ${ }^{\mathrm{b}}$ Department of Aerospace and Systems Engineering, Feng Chia University, Seatwen, Taichung 407, Taiwan, ROC \\ ${ }^{\mathrm{c}}$ Institute of Applied Mechanics, National Taiwan University, Taipei 106, Taiwan, ROC \\ ${ }^{\mathrm{d}}$ Department of Mechanical Engineering, National Chiao-Tung University, Hsinchu 300, Taiwan, ROC \\ Received 28 January 2005; received in revised form 19 September 2005; accepted 19 September 2005 \\ Available online 28 October 2005
}

\begin{abstract}
The objective of this work is to examine the reactant gas transport and the cell performance of a proton exchange membrane fuel cell (PEMFC) with a tapered flow channel design. It is expected that, with the reduction in the channel depth along the streamwise direction, the reactant fuel gas in the tapered channel can be accelerated as well as forced into the gas diffuser layer to enhance the electrochemical reaction and thus augment the cell performance. The effects of liquid water formation on the reactant gas transport are taken into account in the present study. Numerical predictions show that the cell performance can be enhanced with the fuel channel tapered, and the enhancement is more noticeable at a lower voltage. The results also reveal that the liquid water effect in general influences the cell performance and the effect becomes significant at lower voltages.
\end{abstract}

(C) 2005 Elsevier B.V. All rights reserved.

Keywords: PEM fuel cell; Reactant gas transport; Tapered flow channel; Pressure loss

\section{Introduction}

Fuel cell is a class of electro-chemical devices that realizes the direct conversion of chemical energy of reactants to electric energy. With high efficiency and high environment compatibility, the proton exchange membrane (PEM) fuel cell has become a potential candidate of the power source in the near future. There have appeared a number of studies on the transport phenomena and the cell performance of the PEM fuel cells in the open literature. Springer et al. [1] proposed a one-dimensional isothermal model for the PEM fuel cells. In their model, water diffusion coefficient, electro-osmotic drag coefficient, water sorption isotherms and the membrane conductivities were all assumed to be functions of membrane water content. It is found that the membrane resistance increases with the operating current density and, at typical operating conditions, the net water flux ratio is much less than that with a fully hydrated membrane. It is also

\footnotetext{
* Corresponding author.

E-mail address: wmyan@huafan.hfu.edu.tw (W.M. Yan).
}

disclosed that the resistance can be reduced for the membrane thin enough.

Nguyen and White [2] proposed a model with the effects of electro-osmosis, diffusion of water, heat transfer from solid to gas and latent heat of water evaporation/condensation to study the water and thermal management of PEM fuel cells. They found that the ohmic loss is considerable at high current density and the voltage loss is twice amount of that on the cathode electrode. The back diffusion of the water from cathode to anode is not enough to keep the membrane hydrated, therefore, the reactant gas at the anode needs to be humidified. Yi and Nguyen [3] developed an along-the-channel model for evaluating the effects of various designs and operating parameters on the performance of a PEM fuel cell. The results showed that the humidification of the anode gas is required to improve the conductivity of the membrane, and the liquid injection and higher humidification temperature can enhance the cell performance. Additionally, applying higher cathode gas pressure is helpful to replenish the water loss due to electro-osmosis and, thereby, results in more conductive membrane and better cell performance. 


\begin{tabular}{|c|c|}
\hline \multicolumn{2}{|c|}{ Nomenclature } \\
\hline$C$ & mass fraction \\
\hline$C_{\mathrm{F}}$ & quadratic drag factor \\
\hline$D$ & mass diffusivity $\left(\mathrm{m}^{2} \mathrm{~s}^{-1}\right)$ \\
\hline$D_{\mathrm{H}^{+}}$ & $\begin{array}{l}\text { proton diffusivity in membrane } \\
\left(4.5 \times 10^{-9} \mathrm{~atm} \mathrm{~m}^{2} \mathrm{~s}^{-1}\right)(\text { Gurau et al. [19]) }\end{array}$ \\
\hline$D_{\mathrm{H}_{2}}$ & $\begin{array}{l}\text { hydrogen diffusivity }\left(2.63 \times 10^{-6} \mathrm{~m}^{2} \mathrm{~s}^{-1}\right) \\
\text { (Um and Wang [9]) }\end{array}$ \\
\hline$D_{\mathrm{O}_{2}}$ & $\begin{array}{l}\text { oxygen diffusivity }\left(5.2197 \times 10^{-6} \mathrm{~m}^{2} \mathrm{~s}^{-1}\right) \\
\text { (Um and Wang [9]) }\end{array}$ \\
\hline$F$ & Faraday constant $\left(96487 \mathrm{C} \mathrm{mol}^{-1}\right)$ \\
\hline$I$ & current density $\left(\mathrm{A} \mathrm{m}^{-2}\right)$ \\
\hline$j_{0}^{\text {ref }}$ & $\begin{array}{l}\text { reference exchange current density at anode side } \\
\left(5 \times 10^{2} \mathrm{~A} \mathrm{~m}^{-3}\right)(\text { Gurau et al. [19]) }\end{array}$ \\
\hline$k_{\mathrm{c}}$ & $\begin{array}{l}\text { condensation rate constant }\left(\mathrm{s}^{-1}\right) \text { (Mazumder and } \\
\text { Cole [6]) }\end{array}$ \\
\hline$k_{\mathrm{e}}$ & $\begin{array}{l}\text { evaporation rate constant }\left(\mathrm{atm}^{-1} \mathrm{~s}^{-1}\right) \text { (Mazumder } \\
\text { and Cole [6]) }\end{array}$ \\
\hline$k_{\mathrm{p}}$ & permeability $\left(\mathrm{m}^{2}\right)$ \\
\hline$N$ & number of baffles \\
\hline$P$ & pressure $(\mathrm{Pa})$ \\
\hline$R$ & universal gas constant $\left(8.314 \mathrm{~J} \mathrm{~mol}^{-1} \mathrm{~K}^{-1}\right)$ \\
\hline$R_{\mathrm{ch}}$ & $\begin{array}{l}\text { ratio of the outlet channel depth to inlet channel } \\
\text { depth }\end{array}$ \\
\hline$s$ & saturated rate \\
\hline$S$ & source term \\
\hline$T$ & temperature $(\mathrm{K})$ \\
\hline$u$ & velocity in the $x$-direction $\left(\mathrm{m} \mathrm{s}^{-1}\right)$ \\
\hline$v$ & velocity in the $y$-direction $\left(\mathrm{m} \mathrm{s}^{-1}\right)$ \\
\hline$V$ & operating voltage $(\mathrm{V})$ \\
\hline$w$ & oxygen mass fraction \\
\hline$x_{\mathrm{w}}$ & mole fraction of water \\
\hline$Z_{\mathrm{f}}$ & spices valence \\
\hline \multicolumn{2}{|c|}{ Greek letters } \\
\hline$\alpha$ & $\begin{array}{l}\text { transfer coefficient for the reaction }(0.5 \text { on anode } \\
\text { side, } 0.5 \text { on cathode side) }\end{array}$ \\
\hline$\varepsilon$ & porosity \\
\hline$\eta$ & surface overpotential (V) \\
\hline$\rho$ & density $\left(\mathrm{kg} \mathrm{cm}^{-3}\right)$ \\
\hline$\sigma$ & ionic conductivity of the ionomer $\left(\Omega^{-1} \mathrm{~m}^{-1}\right)$ \\
\hline$\tau$ & tortuosity of diffusion layer \\
\hline$v$ & viscosity of flow $\left(\mathrm{kg} \mathrm{m}^{-1} \mathrm{~s}^{-1}\right)$ \\
\hline$v_{\text {air }}$ & $\begin{array}{l}\text { air viscosity }\left(1.58 \times 10^{-5} \mathrm{~kg} \mathrm{~m}^{-1} \mathrm{~s}^{-1}\right) \\
\text { (Gurau et al. [19]) }\end{array}$ \\
\hline$v_{\mathrm{H}_{2} \mathrm{O}}$ & $\begin{array}{l}\text { water viscosity }\left(8.91 \times 10^{-4} \mathrm{~kg} \mathrm{~m}^{-1} \mathrm{~s}^{-1}\right) \\
\text { (Gurau et al. [19]) }\end{array}$ \\
\hline$\phi$ & ionomer phase potential (V) \\
\hline$\Phi$ & phase potential $(\mathrm{V})$ \\
\hline \multicolumn{2}{|c|}{ Subscripts } \\
\hline $\mathrm{a}$ & anode \\
\hline $\mathrm{c}$ & cathode \\
\hline $\mathrm{d}$ & diffuser layer \\
\hline eff & effective \\
\hline
\end{tabular}

\begin{tabular}{|ll|}
\hline & \\
$k$ & $k$ th composition of fuel reactant \\
$\mathrm{L}$ & liquid water \\
$\mathrm{m}$ & membrane \\
$\mathrm{sat}$ & saturated \\
$\mathrm{u}$ & $x$-direct \\
$\mathrm{V}$ & $y$-direct \\
& \\
Superscripts \\
ref & reference \\
\hline
\end{tabular}

Ge and Yi [4] developed a two-dimension model to investigate the effects of operation conditions and membrane thickness on the water transport. In their study, the change in effective porosity with liquid water was considered to simplify the model of the two-phase transport phenomena in porous layers. The results revealed that the cell performance can be enhanced by increasing the cell temperature. Mazumder and Cole [5,6] numerically investigated the cell performance of PEM fuel cells with consideration of the liquid water effects. The results showed that as the current density gets up to a certain critical value, the percentage of the porous media filled with liquid water may exceed $50 \%$, especially at the cathode side.

The flow field designs in bipolar plates are important in the development of the PEM fuel cells. Nguyen [7] proposed a new flow field design to enhance the liquid water transport out of the gas diffuser layer (GDL). This design works by converting the transport of reactant/product gases to/from the catalyst layers from diffusion mechanism to a convection mechanism. Um et al. [8], and Um and Wang [9] developed a multi-dimensional model to study the electrochemical kinetics, current distributions, fuel and oxidant flows, and multi-component transports in a PEMFC with the interdigitated flow field. To understand the effects of the interdigitated gas distributor on the performance of these fuel cell electrodes, Yi and Nguyen [10] employed a two-dimensional isothermal model of a porous electrode to simulate the hydrodynamics of gas flow through the pore volume of the electrode of a PEMFC. It is concluded that, from the predictions of the PEM fuel cells with interdigitated flow field, the higher gas flow rate through the electrode improves the electrode performance.

He et al. [11] studied the influences of electrode and flow field design on the performance of a PEM fuel cell with a half-cell model. It was found that higher differential pressure between inlet and outlet channels would enhance the electrode performance. Increasing the electrode thickness is equivalent to increasing the diameter of a pipe in a fluid flow system and the gas bypass effect becomes more significant. Dohle et al. [12] examined the effects of flow fields on the power density and efficiency of fuel cell systems by conducting experiments and numerical simulations. In their work, the see-through bipolar plate and additional resistance matrix (with simulation) are employed to measure the flow propagation velocity and flow distribution with different permeability. The electrochemical behaviors of a direct methanol fuel cell (DMFC) with serpentine or interdigitated flow field at both 
cathode and anode were investigated by Arico et al. [13]. The experimental results showed that the interdigitated design significantly enhances the mass-transport inside a DMFC and achieves the higher maximum power outputs compared to the classical serpentine geometry. The larger methanol permeation through the electrolyte determines both lower voltage and fuel efficiencies in the activation-controlled region with respect to the serpentine design. Recently, Yan et al. [14,15] studied the effects of flow channel designs on the steady or dynamic gas transport and cell performance of PEM fuel cells. They found that the flow distributor geometry has a significant influence on the cell performance. In addition, they indicated that for a larger channel depth fraction, a faster dynamic response as well as better cell performance can be attained.

Recently, Yan and co-workers $[16,17]$ proposed a new flow field with baffles in the tandem array to augment the reactant transport and cell performance of a proton exchange membrane fuel cell. They found that the reactant transport and cell performance both can be enhanced by the presence of the baffles in the flow channel of the bipolar plate, especially at the operating conditions of low voltage. The beneficial baffle effects become increasingly remarkable with increasing width and/or number of baffles in the tandem array. Soong et al. [18] proposed a relatively novel configuration of partially blocked fuel channels. The blockage effects with various gap ratios and baffle num- bers on the reactant gas transport and the pressure loss across the channel length were emphasized. It was found that reducing gap size and/or increasing baffle number to enhance the reactant gas transport may result in a penalty of high pressure-loss. Very high pressure-loss can be generated due to high flow resistance at a low gap ratio combined with a low GDL porosity. They also proposed reasonable combinations of the influential design parameters.

From the literature survey presented above, it is found that the forced convection of fuel due to channel blockage always leads to a pressure loss. To improve the performance of PEM fuel cells but with the penalty of high pressure-loss alleviated is one of the significant issues in development of the fuel cell technology. The partially blocked channel design studied previously is one of the trials and other possibilities are still open. The objective of the present study is to investigate a new design of fuel channel with tapered configuration in main flow direction. A two-dimensional numerical model of PEMFC with tapered flow channel design at cathode is developed to employee to perform the exploration of the resultant transport phenomena and cell performance.

\section{Analysis}

The schematic diagram of the physical system under consideration is shown in Fig. 1, in which the PEMFC consists of a

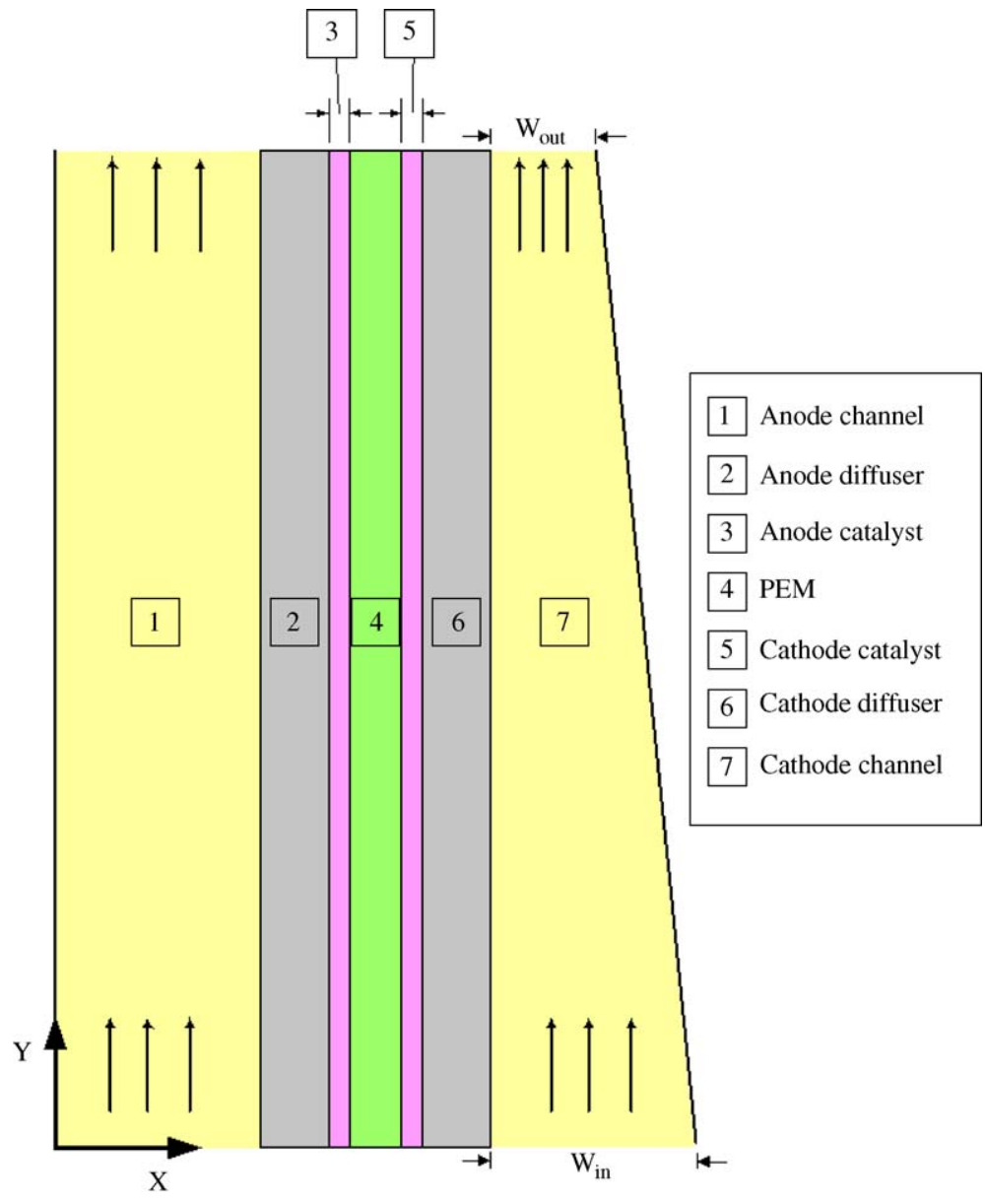

Fig. 1. Schematic diagram of 2D PEMFC model. 
Table 1

Detailed expressions of the source terms in the governing equations

\begin{tabular}{|c|c|c|c|c|c|}
\hline & $S_{\mathrm{u}}$ & $S_{\mathrm{V}}$ & $S_{\mathrm{c}}$ & $D_{k, \text { eff }}$ & $\tau_{i}$ \\
\hline Flow channel & 0 & 0 & 0 & - & - \\
\hline Diffuser layer & $-\frac{v \varepsilon_{\mathrm{eff}}^{2}}{k_{\mathrm{p}}} u-\frac{\varepsilon_{\mathrm{eff}}^{3} C_{\mathrm{F}} \rho u}{\sqrt{k_{\mathrm{p}}}} \sqrt{u^{2}+v^{2}}$ & $-\frac{v \varepsilon_{\mathrm{eff}}^{2}}{k_{\mathrm{p}}} v-\frac{\varepsilon_{\mathrm{eff}}^{3} C_{\mathrm{F}} \rho v}{\sqrt{k_{\mathrm{p}}}} \sqrt{u^{2}+v^{2}}$ & 0 & $D_{k} \varepsilon_{\mathrm{d}, \mathrm{eff}}^{\tau_{i}}$ & 1.5 \\
\hline Catalyst layer & $-\frac{v \varepsilon_{\mathrm{eff}}^{2}}{k_{\mathrm{p}}} u-\frac{\varepsilon_{\mathrm{eff}}^{3} C_{\mathrm{F}} \rho u}{\sqrt{k_{\mathrm{p}}}} \sqrt{u^{2}+v^{2}}$ & $-\frac{v \varepsilon_{\mathrm{eff}}^{2}}{k_{\mathrm{p}}} v-\frac{\varepsilon_{\mathrm{eff}}^{3} C_{\mathrm{F}} \rho v}{\sqrt{k_{\mathrm{p}}}} \sqrt{u^{2}+v^{2}}$ & $H_{2}:-\frac{1}{2 F C_{\mathrm{a}}} j_{\mathrm{a}}$ & $D_{k} \varepsilon_{\mathrm{c}, \text { eff }}^{\tau_{i}}$ & 1.5 \\
\hline & & & $\begin{array}{l}\mathrm{O}_{2}:-\frac{1}{4 F C_{\mathrm{c}}} j_{\mathrm{c}} \\
\mathrm{H}_{2} \mathrm{O}: \frac{1}{2 F C_{\mathrm{c}}} j_{\mathrm{c}}\end{array}$ & & \\
\hline PEM & $\begin{array}{l}-\frac{v \varepsilon_{\mathrm{eff}}^{2}}{k_{\mathrm{p}}} u-\frac{\varepsilon_{\mathrm{eff}}^{3} C_{\mathrm{F}} \rho u}{\sqrt{k_{\mathrm{p}}}} \sqrt{u^{2}+v^{2}} \\
+\frac{k_{p}}{v} Z_{\mathrm{f}} C_{\mathrm{H}^{+}} F \nabla \Phi \frac{\partial u}{\partial x}\end{array}$ & $\begin{array}{l}-\frac{v \varepsilon_{\mathrm{eff}}^{2}}{k_{\mathrm{p}}} v-\frac{\varepsilon_{\mathrm{eff}}^{3} C_{\mathrm{F}} \rho v}{\sqrt{k_{\mathrm{p}}}} \sqrt{u^{2}+v^{2}} \\
+\frac{k_{\mathrm{p}}}{v} Z_{\mathrm{f}} C_{\mathrm{H}^{+}} F \nabla \Phi \frac{\partial v}{\partial x}\end{array}$ & $\frac{Z F}{R T} D_{k, \mathrm{eff}, \mathrm{H}^{+}} C_{\mathrm{H}^{+}}\left(\frac{\partial^{2} \Phi}{\partial x^{2}}+\frac{\partial^{2} \Phi}{\partial y^{2}}\right)$ & $D_{k} \varepsilon_{\mathrm{m}, \text { eff }}^{\tau_{i}}$ & 6 \\
\hline
\end{tabular}

proton exchange membrane in the middle, and two catalyst layers, two gas diffuser layers, and two flow channels each at the anode/cathode side. It is seen that the flow channel depth at the cathode side reduces gradually along the main flow direction. At the cathode side, the reduction in flow area of the fuel channel will force the reactant gas transfer to GDL and catalyst layer as well as increase the forced convection in the flow direction. Firstly, the forced convection in diffuser layer would generate the shear stress to remove the liquid water and heat to reduce the problem of water and thermal management in the PEM fuel cell. Secondly, the reactant gas is easier to react in the catalyst layer, which in turn, causes a better cell performance. Therefore, it is appealing to have a numerical study on the effects of tapered flow channel design on the cell performance of PEM fuel cells. To simplify the analysis in the present study, the following assumptions are invoked: (1) the gas mixtures are considered to be perfect gases; (2) the gas flow is steady and laminar everywhere in the cell; (3) the gas diffuser layers, catalyst layers, and the membrane are considered to be isotropic porous media; (4) the volume of liquid water in the PEM fuel cell is negligible; and (5) the heat generated by chemical reaction is negligible.

With the above assumptions, the gas transport equations for the two-dimensional PEM fuel cell can be described as follows.

Continuity equation:

$\frac{\partial u}{\partial x}+\frac{\partial v}{\partial y}=0$

Momentum equations:

$\varepsilon_{\text {eff }}\left(u \frac{\partial u}{\partial x}+v \frac{\partial u}{\partial y}\right)=-\frac{\varepsilon_{\text {eff }}}{\rho} \frac{\partial P}{\partial x}+v \varepsilon_{\text {eff }}\left(\frac{\partial^{2} u}{\partial x^{2}}+\frac{\partial^{2} u}{\partial y^{2}}\right)+S_{\mathrm{u}}$

$\varepsilon_{\text {eff }}\left(u \frac{\partial v}{\partial x}+v \frac{\partial v}{\partial y}\right)=-\frac{\varepsilon_{\text {eff }}}{\rho} \frac{\partial P}{\partial y}+v \varepsilon_{\text {eff }}\left(\frac{\partial^{2} v}{\partial x^{2}}+\frac{\partial^{2} v}{\partial y^{2}}\right)+S_{\mathrm{V}}$

Species concentration equation

$\varepsilon_{\text {eff }}\left(u \frac{\partial C_{k}}{\partial x}+v \frac{\partial C_{k}}{\partial y}\right)=D_{k, \text { eff }}\left(\frac{\partial^{2} C_{k}}{\partial x^{2}}+\frac{\partial^{2} C_{k}}{\partial y^{2}}\right)+S_{\mathrm{c}}+S_{\mathrm{L}}$
The source terms, $S_{\mathrm{u}}, S_{\mathrm{v}}$ and $S_{\mathrm{c}}$, in the momentum and species concentration equations are listed in Table 1. Among them, the source terms $S_{\mathrm{u}}$ and $S_{\mathrm{v}}$ account for the Darcy's drag forces in the $x$ - and $y$-directions, respectively. The parameter $\varepsilon_{\text {eff }}$ stands for the effective porosity, $C_{\mathrm{F}}$ the quadratic drag factor, $k_{\mathrm{p}}$ the permeability, and $D_{k \text {,eff }}$ the effective diffusion coefficient of the $k$ th composition of fuel reactant determined by Bruggerman model from He et al. [11]. In Eq. (4), $S_{\mathrm{c}}$ and $S_{\mathrm{L}}$ are the source term of chemical reaction and liquid water in the species concentration equation, and $S_{\mathrm{c}}$ is different for the reactant gases, e.g. $S_{\mathrm{c}}$ is $-j_{\mathrm{a}} / 2 F C_{\text {total, a }}$ for hydrogen, $-j_{\mathrm{c}} / 4 F C_{\text {total, }}$ for oxygen, and $-j_{\mathrm{c}} / 2 F C_{\text {total,c }}$ for water vapor. The parameters $j_{\mathrm{a}}$ and $j_{\mathrm{c}}$ indicate the current densities at the anode and cathode sides, respectively, and can be described by the following Butler-Volmer equations [19]:

$j_{\mathrm{a}}=A j_{0}^{\mathrm{ref}}\left(\frac{C_{\mathrm{H}_{2}}}{C_{\mathrm{H}_{2}}^{\mathrm{ref}}}\right)\left[\mathrm{e}^{\left(\alpha_{\mathrm{a}} F / R T\right) \eta}-\frac{1}{\mathrm{e}^{\left(\alpha_{\mathrm{c}} F / R T\right) \eta}}\right]$
$j_{\mathrm{c}}=A j_{0}^{\mathrm{ref}}\left(\frac{C_{\mathrm{O}_{2}}}{C_{\mathrm{O}_{2}}^{\mathrm{ref}}}\right)\left[\mathrm{e}^{\left(\alpha_{\mathrm{a}} F / R T\right) \eta}-\frac{1}{\mathrm{e}^{\left(\alpha_{\mathrm{c}} F / R T\right) \eta}}\right]$

In the above equations, $A j_{0}^{\text {ref }}$ is the reference exchange current density, $\alpha_{\mathrm{a}}$ and $\alpha_{\mathrm{c}}$ are the electric charge transport rates in anode and cathode catalyst layers, $\eta$ is the overpotential, $F$ the Faraday's constant, $R$ the gas constant and $T$ the temperature of the fuel cell. The parameters used are listed in Table 2 .

In order to evaluate the distributions of the local current density, the following phase potential equation is employed,

$\frac{\partial}{\partial x}\left(\sigma_{\mathrm{m}} \frac{\partial \Phi}{\partial x}\right)+\frac{\partial}{\partial y}\left(\sigma_{\mathrm{m}} \frac{\partial \Phi}{\partial y}\right)=S_{j}$

As for the transport equation of the proton in the membrane, one has

$$
\begin{aligned}
\varepsilon_{\mathrm{m}}\left(u \frac{\partial C_{k}}{\partial x}+v \frac{\partial C_{k}}{\partial y}\right)= & D_{i, \mathrm{eff}}\left(\frac{\partial^{2} C_{k}}{\partial x^{2}}+\frac{\partial^{2} C_{k}}{\partial y^{2}}\right) \\
& +\frac{Z F}{R T} D_{i, \mathrm{eff}, \mathrm{H}^{+}} W_{\mathrm{H}^{+}}\left(\frac{\partial^{2} \Phi}{\partial x^{2}}+\frac{\partial^{2} \Phi}{\partial y^{2}}\right)
\end{aligned}
$$


Table 2

Parameters used in this work (Gurau et al. [19])

\begin{tabular}{ll}
\hline Porosity of diffuser layer & 0.4 \\
Permeability of diffuser layer & $1.76 \times 10^{-11} \mathrm{~m}^{2}$ \\
Porosity of catalyst layer & 0.4 \\
Permeability of catalyst layer & $1.76 \times 10^{-11} \mathrm{~m}^{2}$ \\
Porosity of membrane & 0.28 \\
Permeability of membrane & $1.58 \times 10^{-18} \mathrm{~m}^{2}$ \\
Baffle width & $0.000762 \mathrm{~m}$ \\
Channel length & $0.0762 \mathrm{~m}$ \\
Channel depth (anode side) & $0.000762 \mathrm{~m}$ \\
Diffuser layer thickness & $0.000254 \mathrm{~m}$ \\
Catalyst layer thickness & $0.0000287 \mathrm{~m}$ \\
Membrane thickness & $0.00023 \mathrm{~m}$ \\
Operation temperature & $353 \mathrm{~K}$ \\
Operation pressure & $1 \mathrm{~atm}$ \\
Inlet average velocity $\left(v_{0}\right)$ & $1.76 \mathrm{~m} \mathrm{~s}$ \\
Relative humidity(both anode and cathode) & $100 \%$ \\
Cell temperature & $80{ }^{\circ} \mathrm{C}$ \\
Anode fuel & $\mathrm{H}_{2}$ \\
Cathode fuel & Air \\
\hline
\end{tabular}

where $\Phi$ is the phase potential and $\sigma_{\mathrm{m}}$ is the electric conductivity of the membrane which can be calculated by the formulas developed by Springer et al. [1]:

$\sigma_{\mathrm{m}}(T)=\sigma_{\mathrm{m}}^{\mathrm{ref}} \exp \left[1268\left(\frac{1}{303}-\frac{1}{T}\right)\right]$

where the reference electric conductivity is

$\sigma_{\mathrm{m}}^{\mathrm{ref}}=0.005139 \lambda-0.00326$

$\lambda= \begin{cases}0.043+17.81 a-39.85 a^{2}+36.0 a^{3} & 0 \leq a \leq 1 \\ 14+1.4(a-1) & 1<a \leq 3\end{cases}$

In Eq. (11), $a=x_{\mathrm{H}_{2} \mathrm{O}} P / P_{\text {sat }}$ is the activity of water and the saturation at the pressure of water $P_{\text {sat }}$ is calculated by the following equation [1],

$P_{\text {sat }}=10^{-2.1794+0.02953 T-9.1837 \times 10^{-5} T^{2}+1.4454 \times 10^{-7}}$

Using the following relations between the phase potential $\Phi$ and current density $i$,

$i_{x}=-\sigma_{\mathrm{m}} \frac{\partial \Phi}{\partial x}$

$i_{y}=-\sigma_{\mathrm{m}} \frac{\partial \Phi}{\partial y}$

Eq. (7) can then be rewritten as

$\frac{\partial i_{x}}{\partial x}+\frac{\partial i_{y}}{\partial y}=S_{j}$

The water management is very important to the performance of PEM fuel cells. In practice, the liquid water in the porous material could occupy the pore and thus reduce the ability of the gas transport in the porous layers. For simplicity, only the effects of liquid water on the effective porosity and mass diffusivity in the gas diffuser and catalyst layers are taken into account. As the partial pressure of water exceeds the saturation pressure of water, the following equation is used to determine the sources term of liquid water, $S_{\mathrm{L}}[6]$,

$$
S_{\mathrm{L}}= \begin{cases}M_{\mathrm{H}_{2} \mathrm{O}} k_{\mathrm{c}} \frac{\varepsilon_{\mathrm{eff}} C_{\mathrm{H}_{2} \mathrm{O}}}{\rho R T}\left(P_{\mathrm{H}_{2} \mathrm{O}}-P_{\text {sat }}\right), & \text { if } P_{\mathrm{H}_{2} \mathrm{O}}>P_{\text {sat }} \\ k_{\mathrm{e}} \varepsilon_{\mathrm{eff}} s\left(P_{\mathrm{sat}}-P_{\mathrm{H}_{2} \mathrm{O}}\right), & \text { if } P_{\mathrm{H}_{2} \mathrm{O}}<P_{\text {sat }}\end{cases}
$$

where the $k_{\mathrm{c}}$ and $k_{\mathrm{e}}$ are, respectively, the constants of water condensation and evaporation [6], and the $P_{\text {sat }}$ is evaluated by using Eq. (12).

The saturation rate $s$ is employed to express the ratio of the volume of pore occupied by the liquid water to the volume of pore in the porous medium, viz.

$s=\frac{\text { the volume of pore occupied by liquid in porous medium }}{\text { total pore volume in porous medium }}$

The effective porosity of porous medium is modified to account for the liquid water effect,

$\varepsilon_{\mathrm{eff}}=\varepsilon(1-s)$

Boundary conditions for the solutions of the transport equations at the interfaces between different layers of the same domain are not required. At the gas channel outlet, the fully developed flow conditions are assumed,

$u=\frac{\partial v}{\partial y}=\frac{\partial C_{k}}{\partial y}=0$

The boundary conditions at the channel walls and the plate collectors are

$u=v=\frac{\partial C_{k}}{\partial x}=0$

At the interfaces between the gas diffusers and the gas channels, the following boundary conditions are used,

$\left.\varepsilon_{\mathrm{eff}, X^{+}} \frac{\partial v}{\partial x}\right|_{x=X^{+}}=\left.\frac{\partial v}{\partial x}\right|_{x=X^{-}}, \quad v_{x=X^{+}}=v_{x=X^{-}}$

$\left.\varepsilon_{\mathrm{eff}, X^{+}} \frac{\partial C_{k}}{\partial x}\right|_{x=X_{1}^{+}}=\left.\frac{\partial C_{k}}{\partial x}\right|_{x=X_{1}^{-}}, \quad C_{k, x=X^{+}}=C_{k, x=X^{-}}$

The similar conditions are employed for the interface between the gas diffuser and the catalyst layer can be expressed as follows,

$\left.\varepsilon_{\mathrm{eff}, X^{+}} \frac{\partial v}{\partial x}\right|_{x=X^{+}}=\left.\varepsilon_{\mathrm{eff}, X^{-}} \frac{\partial v}{\partial x}\right|_{x=X^{-}}, \quad v_{x=X^{+}}=v_{x=X^{-}}$

$\left.\varepsilon_{\mathrm{eff}, X^{+}} \frac{\partial C_{k}}{\partial x}\right|_{x=X^{+}}=\left.\varepsilon_{\mathrm{eff}, X^{-}} \frac{\partial C_{k}}{\partial x}\right|_{x=X^{-}}$,

$C_{k, x=X^{+}}=C_{k, x=X^{-}}$.

The interface between the catalyst layer and membrane is

$\left.\frac{\partial v}{\partial x}\right|_{\mathrm{CL}}=0,\left.\quad \frac{\partial C_{k}}{\partial x}\right|_{\mathrm{CL}}=0$.

The boundary conditions for the phase potential at the interface between the catalyst layer and the membrane are $\Phi=0$ 
on the anode side and $\partial \Phi / \partial X=0$ on the cathode side. Since the phase potential is a linear distribution in the membrane, the phase potential boundary condition can be written as $\partial \Phi / \partial Y=0$.

\section{Numerical method}

The solution to the governing equations is performed by employing a finite volume scheme with the model domain divided into a number of cells as control volumes. The governing equations are numerically integrated over each of these computational cells or control volumes. The method exploits a collocated cell-centered variable arrangement with the local or cell-averaged values of the physical quantities evaluated and stored at each cell center.

The governing equations can be expressed in the form of a generalized convection-diffusion type of transport equation:

$\nabla\left(\rho \vec{u} \phi-\Gamma_{\phi} \nabla \phi\right)=S_{\phi}$

where $\phi$ denotes the general dependent variable, $\Gamma_{\phi}$ the exchange coefficient, $S_{\phi}$ the source term, $\vec{u}$ the velocity vector, and $\rho$ the density. With the discretization of the governing equations, the coupled finite-difference equations can be expressed in the form of

$a_{P} \phi_{P}=a_{E} \phi_{E}+a_{W} \phi_{W}+a_{N} \phi_{N}+a_{S} \phi_{S}+S_{\phi}$

where $\phi_{P}$ is the value of $\phi$ at the current point $\mathrm{P}, \phi_{E} \cdots \phi_{S}$ stand for the values of the grid points adjacent to the point $\mathrm{P}$, and $a_{P} \cdots a_{S}$ are known as the link coefficients.

In this work, the non-uniform grid system of $72 \times 51$ points is used. To examine the grid independence of the predictions, three grid systems shown in Fig. 2 are considered and their influences on the prediction of local current density distribution for a typical case are presented in Fig. 3. It is found that the maximum deviation among the computations on the grids of $37 \times 26$, $72 \times 51$ and $113 \times 73$ are less than $3 \%$ and the results on $72 \times 51$

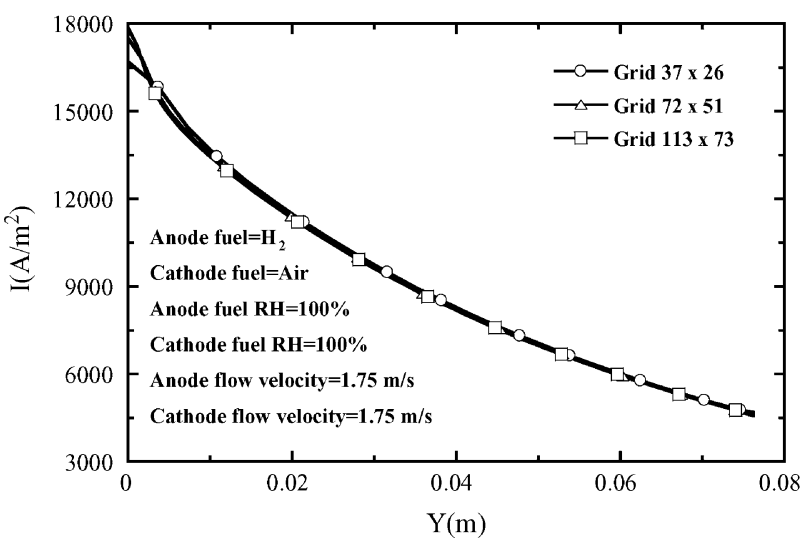

Fig. 3. Comparison of predictions on the three different grid systems.

and $113 \times 73$ grids are quite close. Therefore, the grid system of $72 \times 51$ points seems sufficient to resolve the behaviors of the reactant gas transport in the present PEM fuel cell model.

\section{Results and discussion}

To examine the effects of the tapered flow channel, a parameter, $R_{\mathrm{ch}}$, characterizing the reduction in flow channel depth is defined as the ratio of channel depth at the outlet to that at the inlet. In this work, the channel depth at the inlet is $0.762 \mathrm{~mm}$. Therefore, the channel depths at exit are, respectively, $0.762 \mathrm{~mm}$ for $R_{\mathrm{ch}}=1,0.381 \mathrm{~mm}$ for $R_{\mathrm{ch}}=0.5$ and $0.0762 \mathrm{~mm}$ for $R_{\mathrm{ch}}=0.1$. The effects of $R_{\text {ch }}$ on the $I-V$ and $I-P$ curves are presented in Fig. 4. An overall inspection on Fig. 4 discloses that, under the conditions of the high operating voltages or low current densities, the $R_{\text {ch }}$ effects on the cell performance are negligibly small. At the low operating voltages, however, the variation in $R_{\mathrm{ch}}$ significantly alters the performance curves. Relative to the PEMFC with the channel of uniform width $\left(R_{\mathrm{ch}}=1\right)$, the improvement (a)

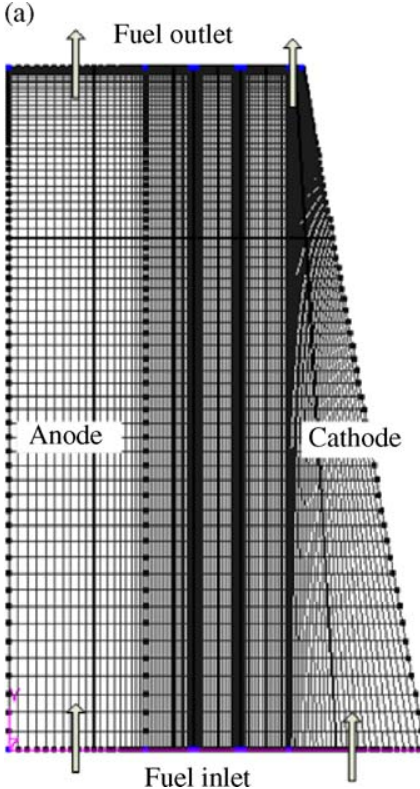

(b)

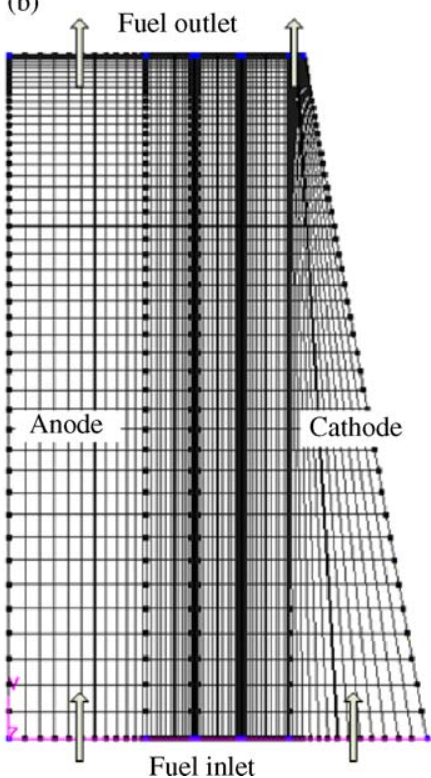

(c)

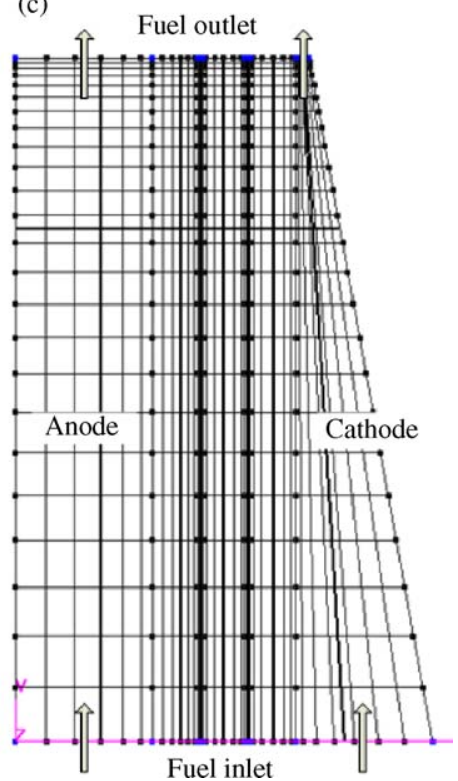

Fig. 2. Mesh structure of three different grid systems of grid points: (a) $113 \times 73$; (b) $72 \times 51$; and (c) $37 \times 26$ 


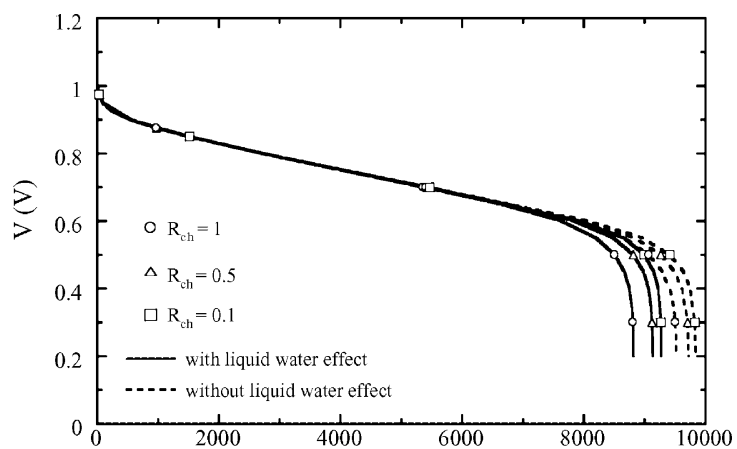

(a)

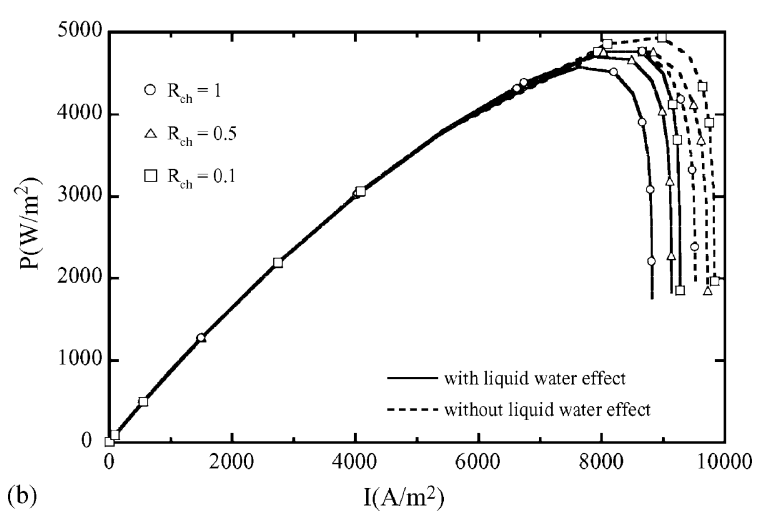

Fig. 4. Effects of $R_{\mathrm{ch}}$ on the cell performance: (a) $I-V$ curves; and (b) $I-P$ curves (note: $P$ stands for power in this plot).
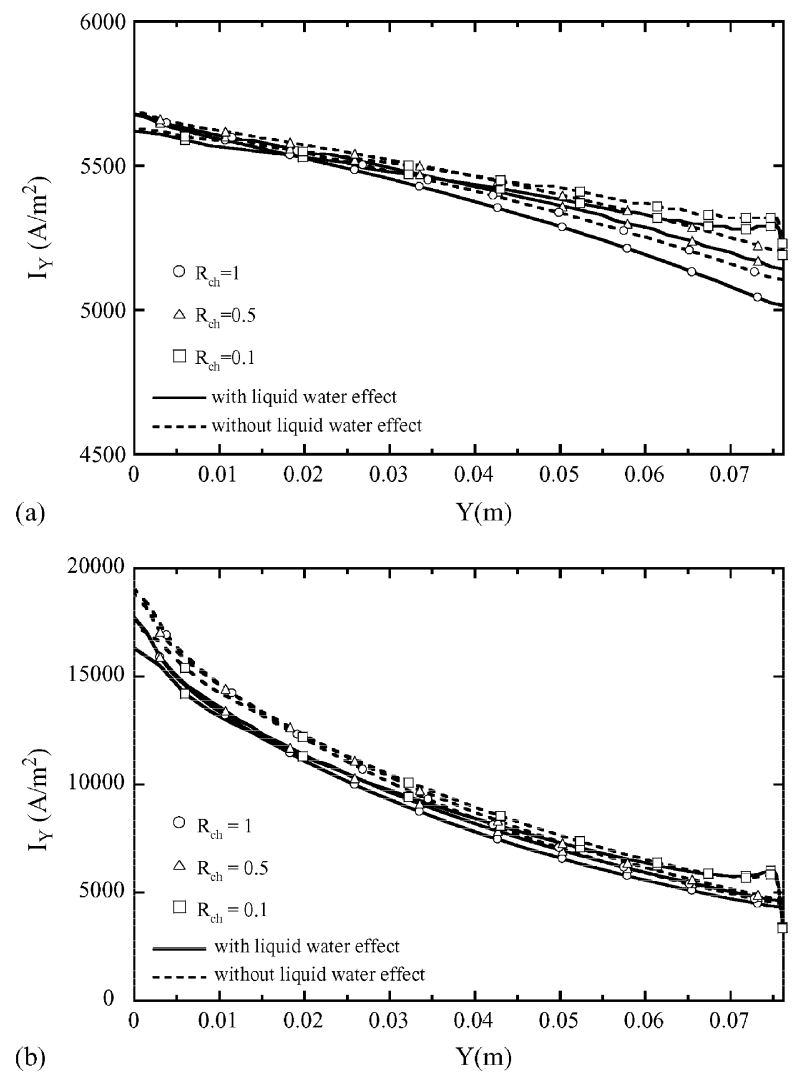

Fig. 5. Effects of $R_{\mathrm{ch}}$ on the local current density distributions at (a) $V=0.7 \mathrm{~V}$; and (b) $V=0.2 \mathrm{~V}$. in the cell performance with the tapered flow channel is demonstrated. It is clearly observed that the smaller the $R_{\mathrm{ch}}$, the higher the limiting current density is. The liquid water effects are also shown in Fig. 4. At high operating voltages, the deviations in the cell performance between the results with and without consideration of liquid water effects are negligible. This means that the fuel transport in the PEM fuel cell can be safely modeled as a single-phase flow. While at low voltages, the liquid water effects on the cell performance become remarkable and cannot be neglected in the modeling. This confirms the fact that the mass transport at lower voltages is more significant and, in turn, more water is generated in the catalyst layer of the cathode side. The two-phase flow effects should be considered at low voltages.

The $R_{\mathrm{ch}}$ effects on the local current density distributions at $V=0.7$ and $0.2 \mathrm{~V}$ are, respectively, presented in Fig. 5(a) and (b), in which the predictions with and without consideration of liquid water are compared with the corresponding cases of the results without liquid water effects. By comparing the ordinates in Fig. 5(a) and (b), it indicates that the variations in the local current density along the flow direction are relatively more noticeable in the cases of a low operating voltage $(V=0.2 \mathrm{~V})$. The electrochemical reaction in the catalyst layer is expected to be stronger at a lower operating voltage or a higher operating current density. Therefore, the reactant oxygen consumes at a higher rate as it flows along the main flow direction, which
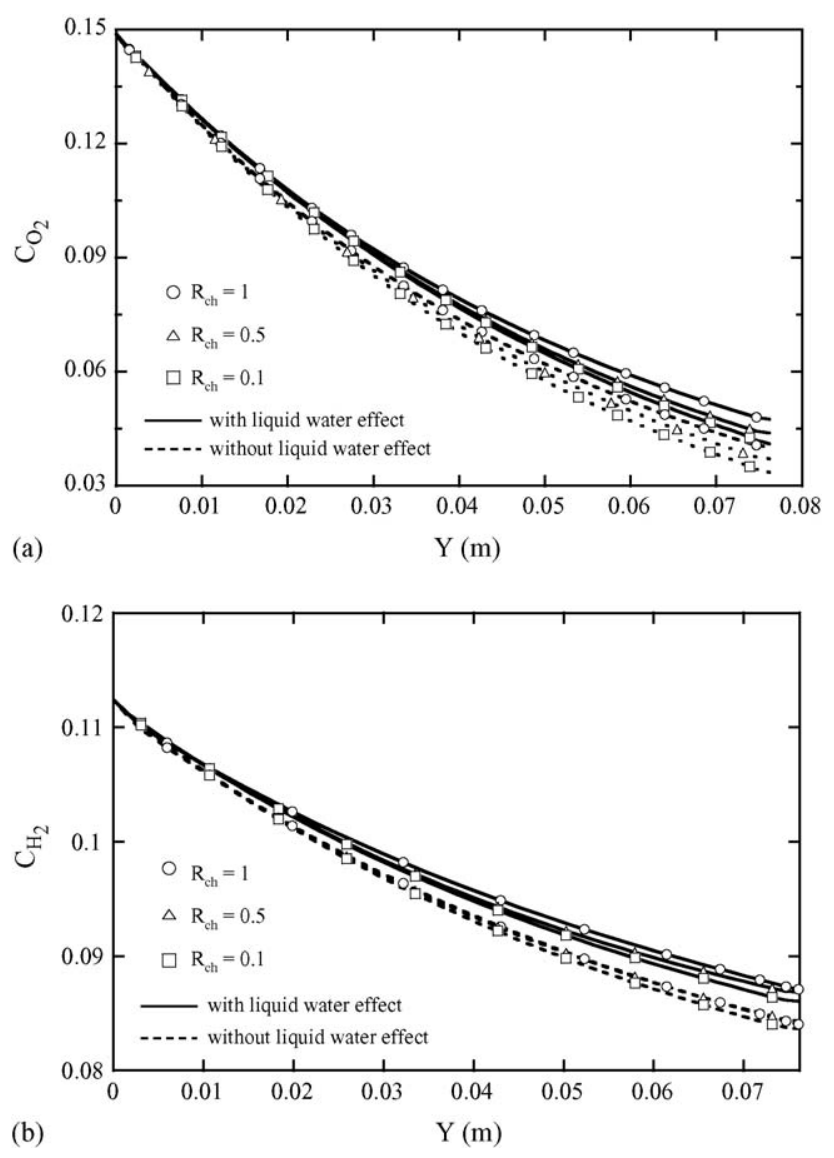

Fig. 6. Effects of $R_{\mathrm{ch}}$ on the local mass fraction distributions along the interface between the GDL and catalyst layer at $V=0.7 \mathrm{~V}$ : (a) oxygen; and (b) hydrogen. 
in turn causes the substantial variations in the local current density. Fig. 5 also discloses that the better cell performance is noted for the fuel channel with a smaller $R_{\mathrm{ch}}$. In addition, the results without consideration of liquid water over-predict the cell performance.

In the study of reactant gas transport in PEM fuel cells, understanding of the detailed distributions of the fuel gases at the interface between the gas diffuser layer and catalyst layer are important to the design of a PEM fuel cell. To this end, the $R_{\text {ch }}$ effects on the local distributions of oxygen and hydrogen mass fractions at the GDL-catalyst interface at operating voltage $V=0.2 \mathrm{~V}$ are presented in Fig. 6 . The oxygen mass fraction on the cathode side decreases along the axial location $Y$ due to the chemical reaction of the oxygen. Results in Fig. 6(a) show that, near the entrance $(Y<0.01 \mathrm{~m})$, the oxygen fraction is lower for the channel with a lower $R_{\mathrm{ch}}(=0.1)$, in which more reactant gas in the downstream part $(Y>0.01 \mathrm{~m})$ of the channel can be forced into the GDL and catalyst layers and thus result in a higher oxygen fraction. It is also found in Fig. 6(a) that the oxygen faction is relatively lower for the case with consideration of the liquid water effects. This is due to the reduction in the oxygen diffusion with the appearance of the liquid water, which in turn causes a lower oxygen fraction. As for the $R_{\mathrm{ch}}$ effects on the anode reactant gas, as shown in Fig. 6(b), the hydrogen mass faction distributions are only slightly affected by the variations
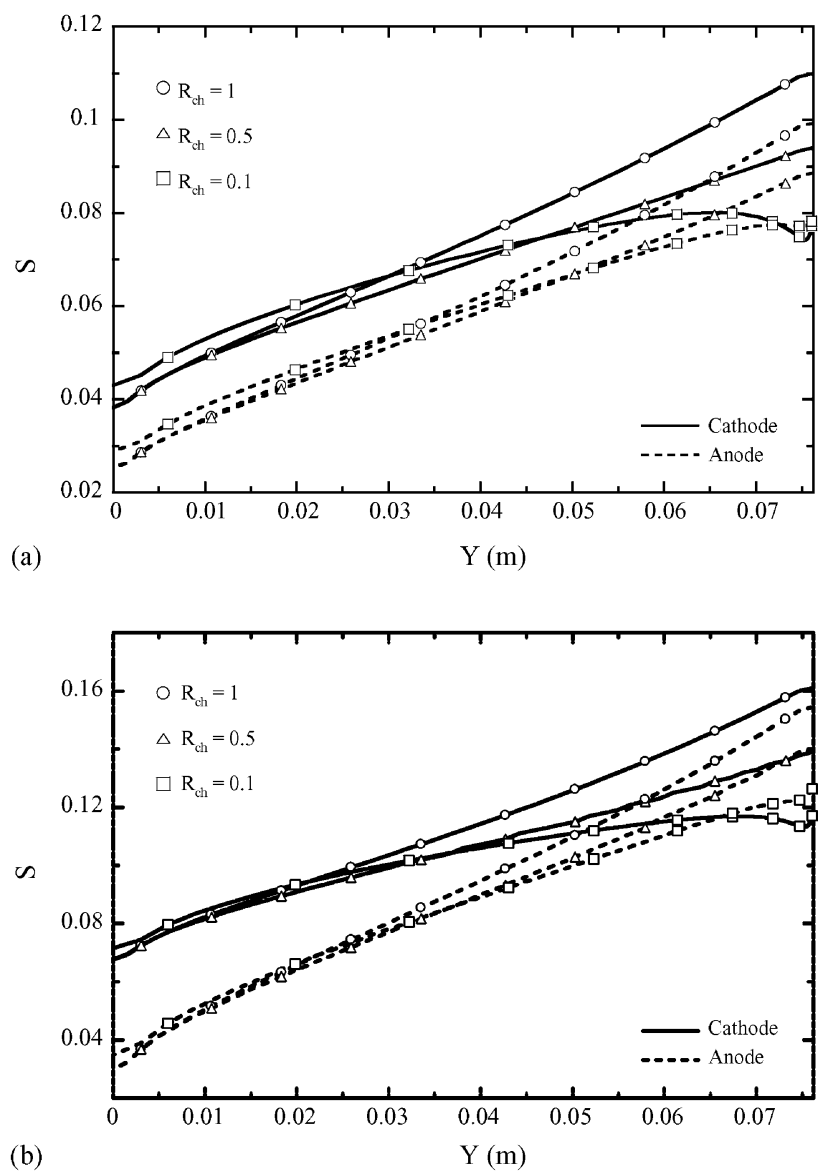

Fig. 7. Effects of $R_{\mathrm{ch}}$ on the local liquid water distributions along the interface between the GDL and catalyst layer at: (a) $V=0.7 \mathrm{~V}$; and (b) $V=0.2 \mathrm{~V}$. in $R_{\mathrm{ch}}$. This confirms the general concept of the negligible effect of the cathode flow field on the anode-side transport phenomena.

Thermal and water management is another important issue pertaining to the performance of PEM fuel cells. To explore the effect of the tapered flow channel on the water content distributions, the liquid water saturations at the GDL-catalyst layer interface for different $R_{\text {ch }}$ are predicted and shown in Fig. 7, in which the solid and dash lines denote the results on the cathode and anode sides, respectively. With the same $R_{\mathrm{ch}}$, the liquid water saturation $S$ is higher in a case of lower operating voltage. This can be made plausible by noting that, for a lower operating voltage (or a higher operating current density), the electrochemical reaction is faster and thus generates more liquid water. The noticeable $R_{\text {ch }}$ effects on the liquid water saturation $S$ are clearly shown in Fig. 7. Near the entrance, the liquid water saturation is slightly higher than the case with a lower $R_{\mathrm{ch}}$. But, as the reactant gas moves downstream, relative to that with conventional uniform flow field, the liquid water saturation with a tapered flow field design is lower. The liquid water saturation decreases with the decrease in $R_{\mathrm{ch}}$. This implies that the use of the tapered flow field can effectively resolve the problem of the water management. In addition, the liquid water saturation on the cathode side is higher than that on the anode side. This is due to the liquid water generation occurring in the catalyst layer on the cathode side.
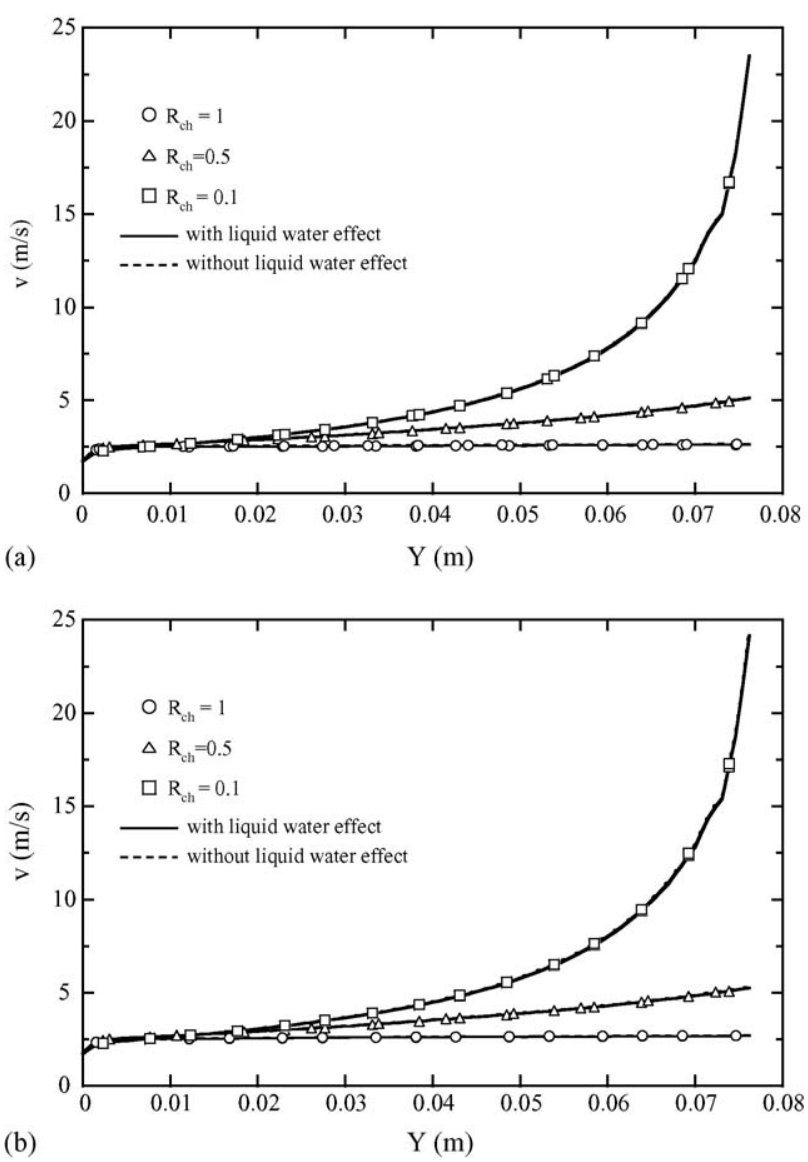

Fig. 8. Effects of $R_{\mathrm{ch}}$ on the local axial velocity distributions at: (a) $V=0.7 \mathrm{~V}$; and (b) $V=0.2 \mathrm{~V}$. 
In order to explain the effectiveness of the tapered channel in the water management, the local velocity distributions for different $R_{\mathrm{ch}}$ are presented in Fig. 8. Here the local velocity, $v(Y)$, is the $Y$-distribution of the axial velocity at the center of the flow channel. It is obviously that the velocity is higher in a tapered channel with a smaller $R_{\mathrm{ch}}$, and the effect becomes strong with the decrease in the value of $R_{\mathrm{ch}}$. Therefore, the removal rate of the liquid water is much more effective for a tapered channel with a smaller $R_{\mathrm{ch}}$. Moreover, there is a sharp increase of velocity, $v$, at $Y>0.070$ since the fuel flow forced into the porous layer must be drained out to channel at $R_{\mathrm{ch}}=0.1$. For this reason, the liquid water saturation $S$ at the GDL-catalyst layer interface decreases slightly at $0.070<Y<0.075$. But at $Y>0.075$ on the GDL-catalyst layer interface near flow exit, the liquid water saturation $S$ increases. This may be due to the fast accumulation of the liquid water from the upstream and the porous layer, which in turn, cause high liquid water saturation $S$.

In analysis of the PEM fuel cell, the pressure drop on the cathode side is one of the key operating parameters to the cell efficiency. To examine this effect, Fig. 9 shows the results of pressure drop on the new flow channel design with different

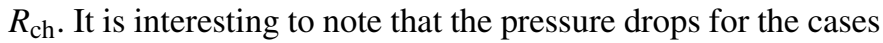
of tapered channels with $R_{\mathrm{ch}}=0.5$ and 0.1 , respectively, are about 2 and 20 times of the uniform-depth channel with $R_{\mathrm{ch}}=1$. Although there seems a considerable difference between the
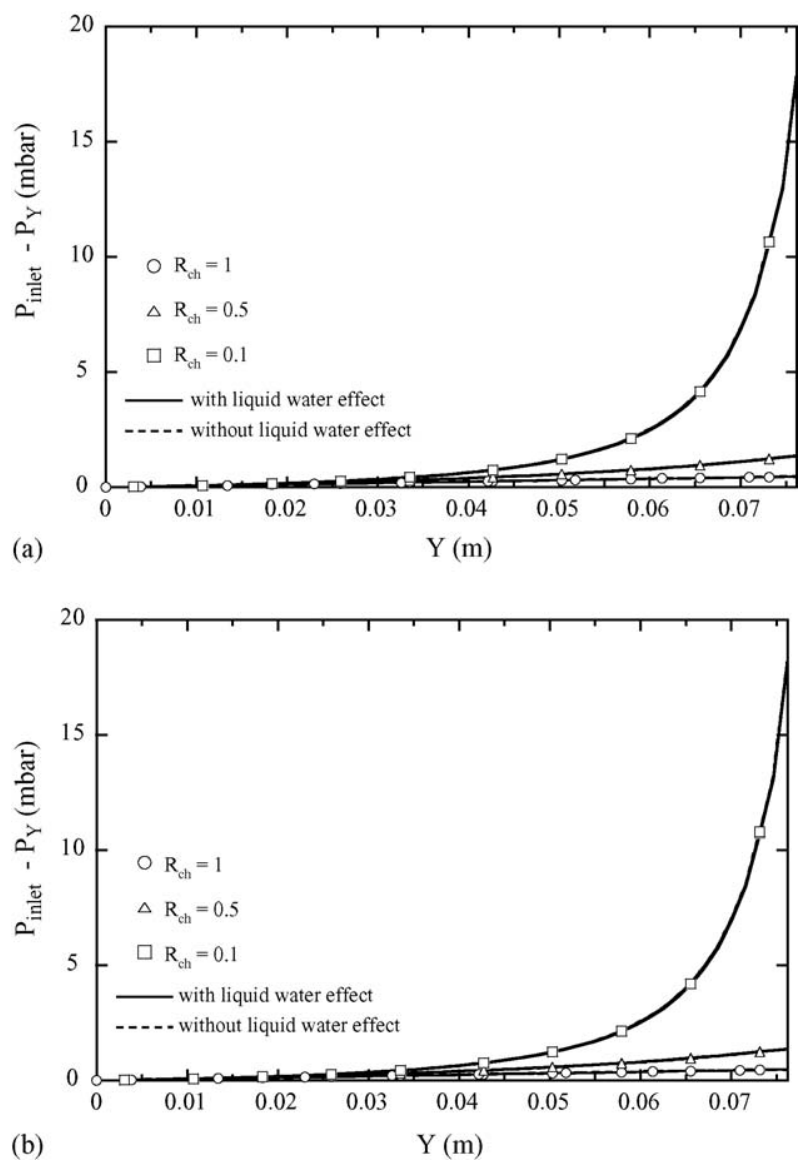

Fig. 9. Effects of $R_{\mathrm{ch}}$ on the pressure drop between gas fuel inlet and outlet in the channel on cathode side. pressure-drops at $R_{\mathrm{ch}}=0.1$ and $R_{\mathrm{ch}}=1$, the value of pressuredrop for $R_{\mathrm{ch}}=0.1$ is only as small as 0.018 bar in the typical cases considered in Fig. 9. That implies a small penalty with the application of the tapered fuel channels.

\section{Concluding remarks}

With an appropriate design of the flow channel in the bipolar plate, the thermal and water management of the PEM fuel cells can be achieved efficiently. To reach this end, a new design of tapered channel with non-uniform depth has been proposed. The performance of the tapered flow fields have been investigated by using numerical predictions of the detailed gas transport phenomena and cell performance of the PEM fuel cells with tapered flow field design. What follows are the major findings.

1. Generally, the application of tapered flow channel design in the bipolar plate of PEM fuel cells leads to a favorable consequence in fuel transport, water management and cell performance. The effects can be enhanced with a decrease in taper ratio of the fuel channel.

2. The beneficial effects of the tapered flow channel become remarkable at the conditions of low operating voltages or high current densities. Therefore, the use of the tapered flow channel will force more reactant gas into the gas diffuser layer and catalyst layer, which in turn results in a better cell performance.

3. It is inevitable that a penalty of pressure-loss accompanies the use of the present tapered channels in flow field design of the bipolar plate. However, the present results disclose that the pressure loss is quite low in general and the potential in practical application of this new flow field design is demonstrated.

4. Finally, the deviations between the predictions with and without consideration of the liquid water effects reveal the influences of the liquid water on the transport phenomena and performance of PEM fuel cells. The present results provide evidences for significance of the liquid water effect and imply the requirement of inclusion of the effect in the modeling and analysis.

\section{Acknowledgements}

The study was supported by the National Science Council, the Republic of China, through the grants NSC 93-2212-E-211-011, NSC 92-2623-7-002-006-ET, 92-2212-E-035-027, and NSC 922212-E-002-096. In addition, the partial financial supports from ITRI and MOEA are also appreciated.

\section{References}

[1] T.E. Springer, T.A. Zawodizinski, S. Gottesfeld, Polymer electrolyte fuel cell model, J. Electrochem. Soc. 138 (1991) 2334-2342.

[2] T.V. Nguyen, R.E. White, A water and heat management model for proton-exchange-membrane fuel cells, J. Electrochem. Soc. 140 (1993) 2178-2186. 
[3] J.S. Yi, T.V. Nguyen, An along-the-channel model for proton exchange membrane fuel cells, J. Electrochem. Soc. 145 (4) (1998) 1149-1159.

[4] S.H. Ge, B.L. Yi, A mathematical model for PEMFC in different flow modes, J. Power Sources 124 (2003) 1-11.

[5] S. Mazumder, J.V. Cole, Rigorous 3-D mathematical modeling of fuel cells I. Model predictions without liquid water transport, Electrochem. Soc. (2003) A1510-A1517.

[6] S. Mazumder, J.V. Cole, Rigorous 3-D mathematical modeling of fuel cells II. Model predictions with liquid water transport, Electrochem. Soc. (2003) A1503-A1509.

[7] T.V. Nguyen, A gas distributor design for proton-exchange-member fuel cells, J. Electrochem. Soc. 143 (5) (1996) L103-L105.

[8] S. Um, C.Y. Wang, K.S. Chen, Computational fluid dynamics modeling of proton exchange membrane fuel cells, J. Electrochem. Soc. 147 (2000) 4485-4493.

[9] S. Um, C.Y. Wang, Three dimensional analysis of transport and reaction in proton exchange membrane fuel cells, The 2000 ASME International Mechanical Engineering Congress \& Exposition, November 5-10, Walt Disney World Dolphin, Orlando, FL, 2000.

[10] J.S. Yi, T.V. Nguyen, Multicomponent transport in porous electrodes of proton exchange membrane fuel cells using the interdigitated gas distributors, J. Electrochem. Sci. 146 (1999) 38-45.

[11] W. He, J.S. Yi, T.V. Nhuyen, Two-phase flow model of the cathode of PEM fuel cells using interdigitated flow fields, AIChE J. 46 (10) (2000) 2053-2064.
[12] H. Dohle, R. Jung, N. Kimiaie, J. Mergel, M. Muller, Interaction between the diffusion layer and the flow field of polymer electrolyte fuel cells-experiments and simulation studies, J. Power Sources 124 (2003) 371-384.

[13] A.S. Arico, P. Creti, V. Baglio, E. Modica, V. Antonucci, Influence of flow field design on performance of a direct methanol fuel cell, J. Power Sources 91 (2000) 202-209.

[14] W.M. Yan, C.Y. Soong, F. Chen, H.S. Chu, Effects of flow distributor geometry and diffusion layer porosity on reactant gas transport and performance of proton exchange membrane fuel cells, J. Power Sources 125 (2004) 27-39.

[15] W.M. Yan, C.Y. Soong, F. Chen, H.S. Chu, Transient behaviors of reactant gas transport and performance of PEM fuel cells, J. Power Sources 143 (2005) 48-56.

[16] H.C. Liu, W.M. Yan, C.Y. Soong, F. Chen, Effects of baffle-blocked flow channel on reactant transport and cell performance of a proton exchange membrane fuel cell, J. Power Sources 142 (2005) 125-133.

[17] J.H. Jang, W.M. Yan, H.Y. Li, Y.C. Chou, Humidity of reactant fuel on the cell performance of PEM fuel cell with baffle-blocked flow field designs, J. Power Sources (2005), in press.

[18] C.Y. Soong, W.M. Yan, C.Y. Tseng, H.C. Liu, F. Chen, Analysis of reactant gas transport in a PEM fuel cell with partially blocked fuel flow channels, J. Power Sources 143 (2005) 36-47.

[19] V. Gurau, H. Liu, S. Kakac, Two-dimensional model for proton exchange membrane fuel cells, AIChE J. 44 (11) (1998) 2410-2422. 